\title{
RESENHA: BERTAZZO, IVALDO. FASES DA VIDA: DA GESTAÇ̃̃ À PUBERDADE. SÃO PAULO: EDIÇÕES SESC SÃO PAULO, 2018, 224P.IL.
}

Pedro José de Freitas Ziroldo ${ }^{\mathrm{i}}$

\begin{abstract}
Resumo: A experiência do corpo é motriz de criações e significados, e é através do corpo que se aprende os sentidos das coisas. O livro Fases da Vida: da gestação à puberdade, de Ivaldo Bertazzo, trata-se de uma obra acessível e destinada a todos os profissionais e cuidadores, desejosos em conhecer as fases do desenvolvimento psicomotor humano. Esta atitude reflexiva e perceptiva nos faz assumir um lugar no processo educacional e convida a nos comprometermos corporalmente no caminho da aprendizagem: nós, educadores e educandos. Repensar (desta vez com o corpo todo) pedagogias a partir da redescoberta da importância do desenvolvimento psicomotor no processo de aprendizagem, faz-nos assumir uma pedagogia "do e para o movimento", imediatamente, também, para a autonomia, o autoconhecimento e a cidadania.
\end{abstract}

Palavras-chave: Psicomotricidade; Corporeidade; Educação; Método Ivaldo Bertazzo.

Abstract: The experience of the body is the generator of creations and meanings and it is through the body that one learns the senses of things. The book Phases of Life: from pregnancy to puberty, by Ivaldo Bertazzo, is a work accessible to all professionals and caregivers, eager to know the stages of human psychomotor development. This (self) reflective and (self) perceptive attitude makes us take a place in the educational process and invites us to commit ourselves bodily to the path of learning: we educators and learners. Rethinking (this time with the whole body) pedagogies from the rediscovery of the importance of psychomotor development in the learning process, makes us assume a "do and for movement" pedagogy, immediately, also for autonomy, self-knowledge and citizenship.

Key-words: Psychomotricity, Corporeality, Education, Ivaldo Bertazzo Method.

\section{Apresentação}

\begin{abstract}
Enquanto tenho um corpo e através dele ajo no mundo, para mim o espaço e o tempo não são uma soma de pontos justapostos, nem tampouco uma infinidade de relações das quais minha consciência operaria a síntese e em que ela implicaria meu corpo; não estou no espaço e no tempo, não penso o espaço e o tempo; eu sou no espaço e no tempo, meu corpo aplica-se a eles e os abarca. (Merleau-Ponty)
\end{abstract}

(c) (i) (2) 2019 Ziroldo. Este é um artigo de acesso aberto distribuído sob os termos da Licença Creative Commons Atribuição Não Comercial-Compartilha Igual (CC BY-NC-4.0), que permite uso, distribuição e reprodução para fins não comercias, com a citação dos autores e da fonte original e sob a mesma licença. 
Desde o final de minha graduação em Psicologia, até a prática profissional enquanto psicólogo e educador, sentia-me um tanto desconfortável e entediado em relação às abordagens teórico-práticas que, durante aqueles anos, nos dedicamos a estudar. Pensar o ser humano e suas relações consigo mesmo, com o outro e o mundo, e ainda propor intervenções nos diferentes âmbitos e espaços onde essas relações acontecem, exigia de mim uma tomada de decisão: eleger uma abordagem teórica e prática, por meio da qual atuaria, e que fosse compatível com a minha cosmovisão. Mas qual concepção de pessoa e mundo, tempo e espaço que construí antes e durante os anos de formação?

Este conflito levou-me a investigar as minhas próprias percepções acerca da subjetividade e relações humanas, e também fez emergir as questões "como estou, como me relaciono, e como ajo no mundo?". Percebi que nunca estive totalmente satisfeito com os modelos de educação e psicologia predominantemente racionalistas, que tendem a subdividir o homem apresentando uma relação de domínio da razão sobre o corpo, e do pensamento sobre a sensibilidade. Apesar de todos os estudos sobre a mente e comportamento humano de que pude tomar conhecimento, sentia falta de algo que, aos poucos, descobri tratar-se da corporeidade ${ }^{2}$.

A corporeidade a que me refiro, pode ser esclarecida a partir da filosofia de MerleauPonty (2011), que a compreende como vivência intencional que nasce da inter-relação sujeito e mundo no campo da experiência.

Merleau-Ponty traz uma nova perspectiva: um olhar fenomenológico do corpo, que difere da dicotomia corpo-alma e da visão corpo-objeto. Para este filósofo, a percepção está relacionada à atitude corpórea. E é através do corpo que se aprende os sentidos e significados das coisas. De modo que a experiência do corpo funda os sentidos, por isso, nesse viés a percepção é entendida, como um acontecimento da corporeidade.

A percepção inaugura a experiência do "corpo próprio" (MERLEAU-PONTY, 2011, p. 205), este não é o mesmo de que fala o positivismo, não é uma coisa ou um objeto, não é um recipiente para a alma e muito menos para a consciência. O corpo próprio é sede de significados, é a maneira pela qual o homem está no mundo, o seu modo de ser e estar a priori. Assim, o primeiro contato do homem com o mundo é sensível porque ele é Revista Interinstitucional Artes de Educar. Rio de Janeiro, V. 5, N.3- pág. 736-744 set-dez de 2019: "Educação: Corpo em movimento." - DOI: 10.12957/riae.2019.46072 
primeiramente um corpo. Olhar para o corpo e vivê-lo dessa maneira dá a chance de saber e aprender sobre o objeto percebido e ao mesmo tempo também de saber e aprender sobre o próprio sujeito que percebe. Ao experimentar o mundo, o homem se reencontra consigo mesmo e se dá conta de sua existência, uma vez que "sou meu corpo" (MERLEAUPONTY, 2011, p. 208).

Assim a subjetividade, antes afastada da sua dimensão corpórea, ganha uma nova significação. Não está "dentro" ou "fora”, mas na relação corpo-mundo. Deste modo, ela talvez não esteja 'em minha cabeça', não está em parte alguma a não ser em meu corpo como coisa no mundo (MERLEAU-PONTY, 2005, p. 21).

Visto que o homem está inserido no mundo com seu corpo em movimento, e que suas relações consigo mesmo, com as coisas, com os outros, com a sua cultura e história se dão por meio de seu corpo, acredito numa educação a partir da experiência corpórea.

Desde que tive contato com o conceito de corporeidade venho descobrindo o caminho de uma possível educação por meio dos sentidos, da experiência vivida, da sabedoria corpórea e do conhecimento psicomotor. O corpo sobre o qual reflito não é um corpo que "temos" ou que podemos "controlar", “ajustar", “condicionar”, como se nele não existisse a vida, mas sim um corpo que somos. O corpo, aqui, é justamente entendido como presença e encontro, situado no mundo, em interação. Um corpo que percebe as coisas e a si mesmo, um corpo social, cultural, histórico, um corpo-linguagem, um corpo-gesto e, por isso, uma corporeidade que é a realização concreta da minha existência aqui-agora.

Muitos de nós, que pensamos e atuamos no campo da educação, apesar de incentivarmos o autoconhecimento e a autonomia, ainda praticamos pedagogias do "não movimento", que duvidam do conhecimento sensível e da experiência corpórea e persistem em exercer um poder sobre o corpo por meio de estratégias de controle e silenciamento do mesmo.

Deste modo, no que tange à educação escolar, foi preciso encontrar recursos teóricos e práticos que conduzissem meus trabalhos na escola rumo a valorizar integral e globalmente o ser humano. Refiro-me ao convite à corporeidade, à experiência sensível e ao conhecimento encarnado para todos os envolvidos no processo educacional, desde os educandos, passando 
pelos professores, equipe pedagógica, até os responsáveis pela alimentação das crianças e demais funcionários que atuam na escola.

Foi neste caminho de redescoberta do corpo em movimento nos processos educacionais que, com afeto, conheci o trabalho de Ivaldo Bertazzo. Digo que foi com afeto em virtude do sentimento de admiração pelos seus anos de trabalho e pesquisa dedicados ao movimento humano e por ter sido afetado, de fato, de forma tão potente por ele, seus conhecimentos e práticas, a ponto de provocar em mim um gesto intencional de repensar os trilhos da educação nos espaços onde estou inserido pessoal e profissionalmente.

Ivaldo Bertazzo, carinhosamente chamado de mago do movimento, é educador e coreógrafo, e está envolvido com a dança e com o gesto humano desde seus 16 anos. É um dos grandes nomes da dança contemporânea brasileira e seu trabalho tem grande importância na história desta arte, bem como nas pesquisas e práticas de reeducação do movimento e desenvolvimento psicomotor.

Bertazzo criou o conceito de Cidadão Corpo, e realiza seus trabalhos com pessoas comuns, o corpo e o gesto tornam-se a manifestação da individualidade de cada um (BERTAZZO, 2015). Dessa maneira incentiva o aluno a ampliar seu conhecimento e consciência sobre o corpo e seus movimentos, partindo da premissa de que todos nós somos Cidadãos Dançantes.

Em 1975 criou a Escola do Movimento - Método Bertazzo, em São Paulo/SP, onde, desde então, oferece aulas e formações "com o objetivo de ampliar a consciência corporal, a autonomia e a estrutura próprias do movimento. $\mathrm{O}$ ensino é replicado para arte-educadores, a fim de multiplicar o método" (BERTAZZO, 2015, p. 250).

Foi numa das formações no Método Bertazzo, direcionada exclusivamente a profissionais da área cultural e artística, principalmente arte-educadores, que pude vivenciar pela primeira vez em meu corpo e perceber as transformações transcorridas em mim, por meio do trabalho proposto e, posteriormente, refletir sobre a importância de suas pesquisas e de seu método para a educação.

Sendo assim, uma vez exposta minha dedicação concreta na construção de uma educação estética e ética, a partir da redescoberta do corpo em movimento e da experiência sensível, e afirmada a minha admiração pelo "Mestre do Movimento" Ivaldo Bertazzo, 
dedicar-me-ei, nos próximos parágrafos, a resenhar o seu livro mais recente, o qual, em minha opinião, pode contribuir qualitativamente na formação de educadores comprometidos com o desenvolvimento integral de seus alunos, atuando como um importante e acessível manual de exercícios e atividades a serem estimulados e praticados no contexto educacional, como promotores de reeducação do movimento e desenvolvimento psicomotor.

\section{Resenha}

O livro Fases da Vida: da gestação à puberdade (BERTAZZO, 2018), segundo o autor, nasceu do sonho de promover a difusão dos conceitos sobre psicomotricidade humana não só aos nossos sistemas de saúde e educação, mas também aos espaços de desenvolvimento pessoal de crianças, jovens e adulto (BERTAZZO, 2018, p. 16).

Considero a obra acessível tanto na sua organização, quanto na sua linguagem e, por isso, parece-me ser destinada a todos os profissionais e cuidadores, desejosos em conhecer as fases do desenvolvimento psicomotor humano, a fim de contribuir para que as crianças e jovens sob seus cuidados descubram-se corpos e, com isso, seus movimentos: motores, cognitivos, afetivos e intelectuais.

Acredito ainda que sua leitura desperta nos leitores, sobretudo nos educadores, uma certa curiosidade ativa sobre o funcionamento psicomotor, primeiro em si próprio, como forma de autoconhecimento e, não muito adiante, em seus educandos. Ao longo da leitura, somos constantemente convidados a experienciar nossas posturas e organização corporal, a descobrir as estruturas e geometrias do corpo, em nosso próprio corpo. Consequentemente, isso também nos incita a refletir sobre o corpo daqueles que estão sob os nossos cuidados.

Esta atitude (auto)reflexiva e (auto)perceptiva nos faz assumir um lugar no processo educacional próprio e do outro, que convida a nos comprometermos corporalmente no caminho da aprendizagem: educadores e educandos. Repensar (desta vez com o corpo todo) pedagogias a partir da redescoberta da importância do desenvolvimento psicomotor no processo de aprendizagem, faz-nos assumir uma pedagogia do e para o movimento, imediatamente, também, para a autonomia, o autoconhecimento e a cidadania. 


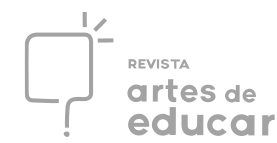

Durante a leitura é possível encontrar várias orientações de exercícios musculares e articulares, bem como sugestões de atividades que trabalham a psicomotricidade.

O livro possui duzentas e vinte quatro páginas e, é dividido em três partes, nas quais estão distribuídos os treze capítulos. Além do material gráfico, a obra conta com uma

websérie $^{3}$, na qual ilustrações e vídeos podem ser acessados por QR codes; os 62 audiovisuais aí contidos contribuem para aprofundar a compreensão do leitor sobre os exercícios psicomotores.

Na primeira parte, o autor se dedica a apresentar, de forma geral, a organização do corpo e sua geometria que, em sua compreensão, são as bases dos gestos humanos. As discussões vão além das estruturas físicas e motoras: passam também pelas questões psíquicas que, em conjunto, caracterizam o ser humano como uma unidade psicomotora. $\mathrm{Na}$ segunda parte, ocorre o detalhamento do desenvolvimento da psicomotricidade humana, desde a gestação até a puberdade. Por fim, na terceira e última parte, dá-se maior atenção à organização do movimento humano.

Na primeira parte do livro, encontram-se os primeiros cinco capítulos. O primeiro traz reflexões sobre o desenho corporal e a gestualidade humana, resultados de uma gama de fatores: desde a herança genética até o universo simbólico que, conjuntamente, lapidaram suas formas e funções, garantindo a nossa sobrevivência. No segundo capítulo, já é possível encontrar os diferentes potenciais e personalidades de cada corpo, e sugere-se a necessidade de acolher e discernir sobre os diferentes modos de existir para melhor estimular o desenvolvimento psicomotor singularmente vivenciado. Se no primeiro capítulo somos convidados a compreender a filogenia do corpo e do gesto humanos, no segundo capítulo somos colocados diante dos processos pessoais e subjetivos de cada corpo, que é entendido aqui como um processo subjetivo que vai formando a si mesmo, um processo vivo e evolutivo, que está em contínua transformação e organização de si mesmo (ibid., p. 30).

No terceiro capítulo, o autor traz detalhes a respeito da estrutura, funcionamento e desenvolvimento do sistema nervoso. Em seguida, no quarto capítulo, mergulha nos elementos psicomotores, especificando cada componente e suas qualidades de acordo com as fases do desenvolvimento humano. No quinto capítulo, descreve a organização postural do corpo humano apoiada nas formas geométricas, o que confere clareza ao entendimento 


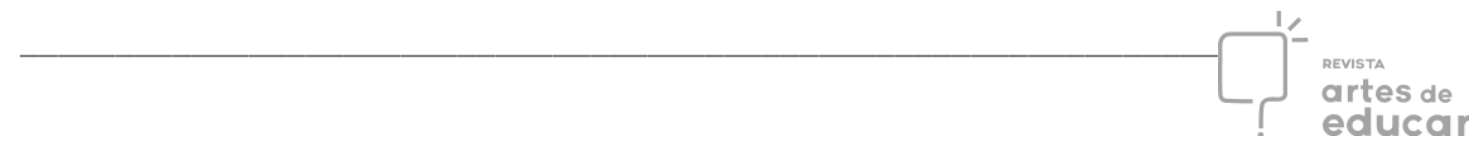

das estruturas apresentadas e uma referência concreta para o trabalho de consciência e percepção do próprio corpo.

Na segunda parte, onde estão agrupados do sexto ao décimo primeiro capítulos, temos a exposição do desenvolvimento psicomotor, bem como de atividades e exercícios que poderiam adequar-se a cada fase da vida humana. Este conjunto parece ser o ápice do livro, no qual o autor oferece generosamente detalhes sobre o desenvolvimento psicomotor e atividades que o estimulam. Detalhes esses que ajudarão os educadores/leitores a embasarem seus trabalhos e intervenções voltados a todas essas etapas da vida.

Funcionará, caso queira o educador, como uma guia de orientações sobre práticas a serem realizadas, conforme a faixa etária com a qual se relaciona em sua prática diária, além de convidá-lo ao autoconhecimento e desenvolvimento de habilidades psicomotoras e psicocomportamentais, que irão se refletir na nossa formação profissional e pessoal.

Na terceira e última parte do livro, Ivaldo Bertazzo nos convence sobre a importância do movimento para o ser humano e, em decorrência disso, reafirma a necessidade de continuar estimulando e reanimando os processos psicomotores aprendidos, experimentados, vivenciados ao longo de todo o desenvolvimento psicomotor. Para o autor, primeiro envelhecem os gestos (ibid., p. 159), por isso, na ausência deles, desfazem-se imagens motoras há muito tempo conquistadas e, com elas, a imagem corporal plena de integridade (ibid., 160). A obra finaliza com uma série de exercícios destinadas aos próprios leitores, com o objetivo "de reavivar a nossa memória motora” (ibid., 160). Mais uma vez, o autor parece se preocupar em garantir que a experiência psicomotora se dê primeiramente no educador e cuidador.

\section{Considerações Finais}

Com Ivaldo Bertazzo, encontro meios de animar a corporeidade como forma de serestar-conhecer o mundo. Então, por que não dizer que o convite a viver e conhecer o corpo de maneira experiencial é também um convite a uma tomada de responsabilidade pelo processo educativo pessoal e social, incluindo a integralidade do humano nesse processo?

Desta mesma forma, o livro Fases da Vida: da gestação à puberdade (BERTAZZO, 2018), faz-nos refletir sobre a importância de uma educação que dá sentido e significado para 


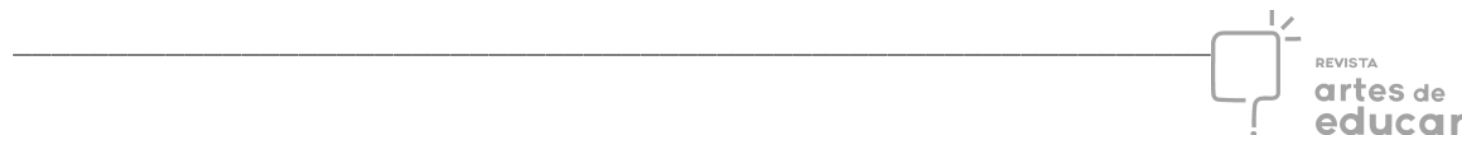

o corpo e seu gesto em todo o processo de formação, como forma de alcançar o desenvolvimento global do humano, desde a dimensão cognitiva, motora, psíquica e afetiva até a social, cultural e política.

Acredito que quando convido o educando a viver o seu corpo, convido-o para um mergulho em sua historicidade, num processo de descoberta de si, pois nossa história é viva e está inscrita em nosso corpo movente. É por meio do corpo que experimentamos todas as coisas, incluindo a nós mesmos, que estamos integralmente presentes em tais experiências. É com este corpo que estamos inseridos no mundo.

Descobrir o corpo e o gesto é descobrir-se vivo e operante, aqui-agora no mundo. Portanto, uma educação do e para o movimento, é uma educação da consciência e a responsabilidade no exercício da cidadania.

Considero, primeiramente, o livro apresentado um importante caminho no processo de autoconhecimento, autonomia e autocuidado dos educadores e cuidadores em geral. A docência se dá de forma presencial, na relação direta com o outro, são seus corpos que interagem com o processo educacional; por isso, a qualidade de sua presença é tema de fundamental relevância quando se pensa em introduzir a dimensão do autocuidado no processo formativo.

Em segundo lugar, o livro traz importantes estratégias que elaboram e estimulam o desenvolvimento psicomotor do educando, contribuindo assim para a sua formação integral. Por fim, trata-se de uma obra que não só propõe a redescoberta do corpo e a reeducação do movimento, mas também nos incita, desde o primeiro parágrafo, a viver nossos corpos e nos movimenta.

Um livro do movimento e em movimento!

\section{REFERÊNCIAS}

BERTAZZO, Ivaldo. Corpo vivo: reeducação do movimento. $2^{\circ}$ ed. São Paulo: Edições Sesc São Paulo, 2015.

BERTAZZO, Ivaldo. Fases da vida: da gestação à puberdade / Ivaldo Bertazzo. São Paulo: Edições Sesc São Paulo, 2018.

HERGESEL, João Paulo. A websérie enquanto processo comunicacional no contexto da cultura da convergência e os alicerces midiáticos necessários para sua roteirização.

REU, Sorocaba,SP, v.41, n. 1, p. 59-78, jun. 2015.

Revista Interinstitucional Artes de Educar. Rio de Janeiro, V. 5, N.3- pág. 736-744 set-dez de 2019: "Educação:

Corpo em movimento." - DOI: 10.12957/riae.2019.46072 
MERLEAU-PONTY, M. Fenomenologia da percepção. São Paulo: Martins Fontes;1996, p.662.

MERLEAU-PONTY, Maurice. Fenomenologia da Percepção. Tradução de C. Moura. $4^{\mathrm{a}}$ ed. São Paulo: Martins Fontes, 2011.

O visível e o invisível. Tradução de A.Gianotti, \& A.

Mora. São Paulo: Perspectiva, 2005.

REEDUCAÇÃO do Gesto Cotidiano. SESC - São Paulo, 2015. Disponível em: <https://www.sescsp.org.br/online/artigo/compartilhar/9078_REEDUCACAO+DO+GEST O+COTIDIANO>. Acesso em: 03 de set. de 2019.

i Pedro José de Freitas Ziroldo. Ator, Educador, Psicólogo e Mestre em Artes da Cena. E-mail: pedroziroldo90@gmail.com.

2 Corporeidade é um conceito do pensamento de Maurice Merleau Ponty (1908-1961), e designa a essência do Ser do Homem, manifestada através do seu corpo.

3 A websérie é uma narrativa produzida em linguagem audiovisual, de maneira seriada, cujos episódios ficam disponíveis para acesso nos espaços online passíveis de circulação, especialmente os sites de armazenamento de vídeos (HERGESEL, 2015, p.60). 